\title{
PRACTICAL ADVANCED ANALYSIS FOR STEEL FRAMES
}

\author{
A. Agüero and F. Pallares \\ Universidad Politecnica de Valencia, Campus Vera s/n, 46020 Valencia, España \\ Email:anagra@mes.upv.es
}

\begin{abstract}
The aim of this paper is to present a practical advanced analysis method for steel frame design, based on a simplified second-order elastic analysis of the structure with an equivalent geometric imperfection. The second order effects are calculated using the orthogonality properties of the buckling modes. The geometric imperfection is obtained from the buckling mode by a suitable scaling procedure using a generalization of Dutheil's method.
\end{abstract}

Keywords: Advanced analysis, Geometric nonlinearity, Steel design, Steel frames, Geometric imperfection.

\section{INTRODUCTION}

The buckling analysis and design of steel frames requires to take into account: geometric and material nonlinearities. The geometric nonlinearity includes second-order effects associated with P$\delta$ and P- $\Delta$ effects and geometric imperfections. The material nonlinearity includes gradual yielding associated with the influence of residual stresses and flexure (Figure 1).
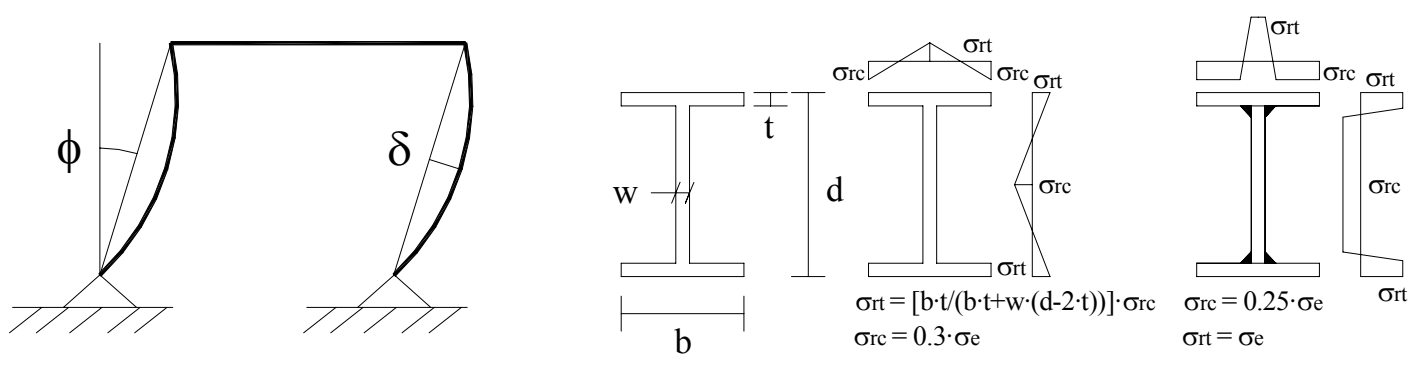

Figure 1. member imperfection $(\delta)$, frame imperfection $(\Phi)$ and residual stress diagrams

To obtain the collapse load of the structure some of these factors can be taken into account in a simplified way, for example by means of equivalent imperfections. In the present proposal a geometric equivalent imperfection is used to consider the residual stress, the geometric imperfection and the nonlinear constitutive behavior.

As shown in Figure 2, the Eurocode-3 [1] proposes a second order analysis of imperfect structures with two type of imperfections, member $\{\delta\}$ and frame $\{\Phi\}$, the local imperfection can sometimes be neglected in the global analysis and considered by means of the proper design formula with an auxiliary coefficient " $\chi$ ".

The method presented in this paper is based on:

1. A linear analysis of the structure used to obtain the primary internal forces and moments.

2. An initial stability analysis used to obtain the secondary internal forces and moments.

3. The analysis is limited to the elastic range and the computed collapse load is equal to the one causing the formation of the first plastic hinge or yield, depending on the use of the plastic (Class 2) or elastic (Class 3) section modulus.

The formation of the first plastic hinge can be expressed as Chen [2]:

$\left(\frac{M_{Z}^{K B}}{M_{z p l}^{K B}}\right)^{\alpha}+\left(\frac{M_{Y}^{K B}}{M_{y p l}^{K B}}\right)^{\beta} \leq 1$ 
Or in a conservative way as:

$$
\frac{N_{K B}}{N_{p l}^{K B}}+\frac{M_{Z}^{K B}}{M_{z p l}^{K B}}+\frac{M_{Y}^{K B}}{M_{y p l}^{K B}}+\frac{B i^{K B}}{B i_{p l}^{K B}}=1
$$

4. The orthogonality properties of the buckling modes are used to simplify the analysis.

5. A generalization of Dutheil's method is used to obtain the geometric equivalent imperfection.

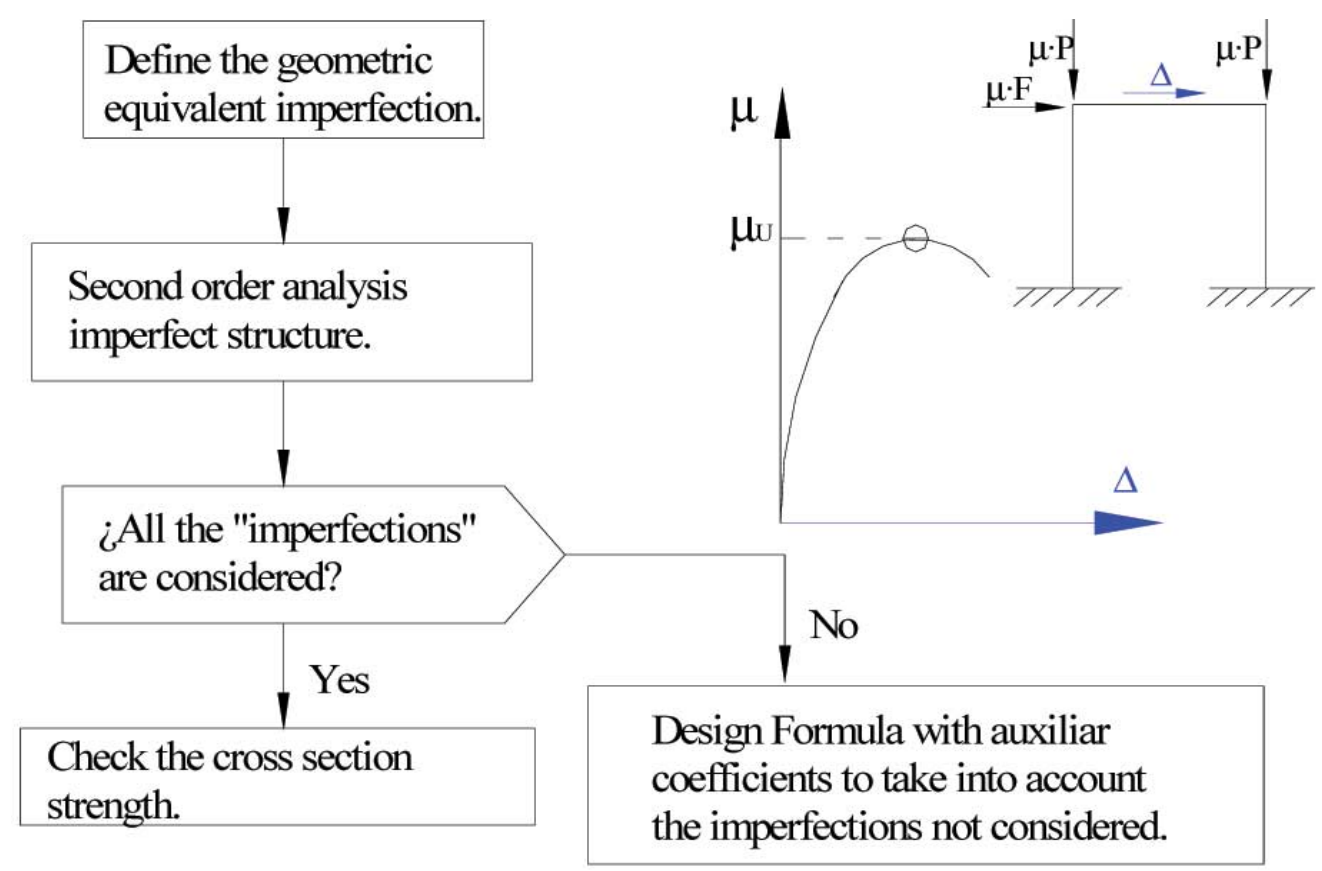

Figure 2. Frame analysis according to Eurocode

The proposed method can be applied easily to the design of practical structures due to its compatibility with the design code requirements and its simplicity, and like the practical advanced analysis methods proposed by Chan [3] and Kim [4] it does not require tedious separate member capacity checks so it can find its way into practice.

\section{DESCRIPTION OF THE PROPOSED METHOD}

In first place the nonlinear geometric analysis of imperfect structures is described, giving a simplified way of analysis, using the orthogonality properties of the bucking modes. In second place a methodology is proposed to obtain the geometric equivalent imperfection.

\section{Nonlinear analysis of the structure with geometric imperfections}

The governing equilibrium equations of the imperfect prismatic beam column with primary constant axial $\{P\}$ and constant strong bending moment $\{M y\}$, and small distributed loads $\left\{p_{x}, p_{y}\right.$, $\left.\mathrm{p}_{\mathrm{z}}, \mathrm{m}_{\mathrm{x}}\right\}$ are:

$$
\begin{gathered}
E A \frac{d^{2} u}{d x^{2}}=-\mathrm{p}_{x} \\
\text { EIy } \frac{d^{4} w}{d x^{4}}+P \frac{d^{2} w}{d x^{2}}=-P \frac{d^{2} w_{i}}{d x^{2}}+p_{z}
\end{gathered}
$$




$$
\begin{gathered}
E I z \frac{d^{4} v}{d x^{4}}+M y \frac{d^{2} \theta_{x}}{d x^{2}}+P \frac{d^{2} v}{d x^{2}}=-M y \frac{d^{2} \theta_{x i}}{d x^{2}}-P \frac{d^{2} v_{i}}{d x^{2}}+p_{y} \\
\left(-G I t+\operatorname{Pr}_{o}{ }^{2}\right) \frac{d^{2} \theta_{x}}{d x^{2}}+M y \frac{d^{2} v}{d x^{2}}+E I a \frac{d^{4} \theta_{x}}{d x^{4}}=-\operatorname{Pr}_{o}{ }^{2} \frac{d^{2} \theta_{x i}}{d x^{2}}-M y \frac{d^{2} v_{i}}{d x^{2}}+m_{x}
\end{gathered}
$$

The displacements are given by:

$$
\begin{aligned}
& u(x)=a_{1}+a_{2} x-\frac{p_{x}}{2 E A} x^{2} \\
& v(x)=a_{3} \operatorname{senh}(\mu x)+a_{4} \cosh (\mu x)+a_{5} \cdot \operatorname{senh}(\beta x)+a_{6} \cdot \cosh (\beta x)+a_{7}+a_{8} x \\
& +\frac{M_{x}+p_{y}\left(G I t-P r_{o}^{2}\right)}{2\left(P\left(G I t-P r_{o}^{2}\right)+M y^{2}\right)} x^{2}+v_{i a}(x) \\
& w(x)=a_{9}+a_{10} x+a_{11} \cos (k x)+a_{12} \operatorname{sen}(k x)+\frac{p_{z}}{2 P} x^{2}+w_{i a}(x) ; k=\sqrt{\frac{P}{E I y}} \\
& \theta_{x}(x)=\eta\left(a_{3} \operatorname{senh}(\mu x)+a_{4} \cosh (\mu x)\right)+\psi\left(a_{5} \operatorname{senh}(\beta x)+a_{6} \cosh (\beta x)\right)+a_{13}+a_{14} x \\
& +\frac{M y p_{y}-m_{x} P}{2\left(P\left(G I t-P r_{o}^{2}\right)+M y^{2}\right)} x^{2}+\theta_{x i a}(x) \\
& \mu=\frac{\sqrt{\rho-P\left(\text { Izro }_{o}^{2}+I a\right)+\sqrt{4 I z I a M y^{2}+\rho^{2}+2 P \rho\left(I a-\text { Izro }^{2}\right)+P^{2}\left(\text { Izro }^{2}\left(\text { Izro }^{2}-2 I a\right)+I a^{2}\right)}}}{\sqrt{2 E I z I a}} \\
& \beta=\frac{\sqrt{\rho-P\left(\text { Izro }_{o}^{2}+I a\right)-\sqrt{4 I z I a M y^{2}+\rho^{2}+2 P \rho\left(\text { Ia }^{2} \text { Izro }^{2}\right)+P^{2}\left(\text { Izro }^{2}\left(\text { Izro }^{2}-2 I a\right)+I^{2}\right)}}}{\sqrt{2 E I z I a}} \\
& \eta=-\frac{E I z \mu^{2}+P}{M y} ; \psi=-\frac{E I z \beta^{2}+P}{M y} ; \rho=G I z I t
\end{aligned}
$$

If the imperfection $\left\{\mathrm{v}_{\mathrm{i}}, \mathrm{w}_{\mathrm{i}}, \theta_{\mathrm{xi}}\right\}$ is given by the first bucking mode the solution associated with the imperfection $\left\{\mathrm{v}_{\mathrm{ia}}, \mathrm{w}_{\mathrm{ia}}, \theta_{\mathrm{xia}}\right\}$ is:

$$
v_{i a}=\frac{v_{i}}{\mu_{1 M N}-1} ; w_{i a}=\frac{w_{i}}{\mu_{1 M N}-1} ; \theta_{x i a}=\frac{\theta_{x i}}{\mu_{1 M N}-1}
$$

Several authors have studied the effect of imperfections on the behaviour of steel frames, Clarke et al. [5] showed that the worst shape was the one given by the first buckling mode. In case of Figure 3 this imperfection is for the frame D and for the cantilever E.
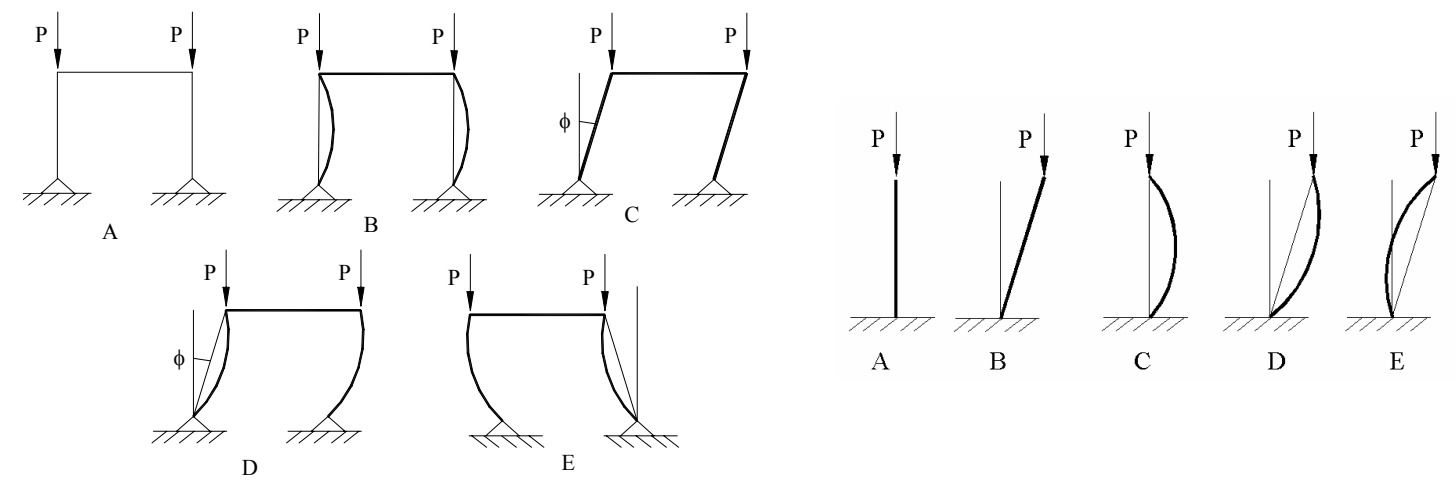

Figure 3. Different patterns of imperfection in a frame and a cantilever. 
The consistent internal forces are:

$$
\begin{gathered}
N=E A \frac{d u}{d x} \\
Q y=-E I z \frac{d^{3} v}{d x^{3}}-M y \frac{d\left(\theta_{x}+\theta_{x i}\right)}{d x}-P \frac{d\left(v+v_{i}\right)}{d x} \\
Q z=-E I y \frac{d^{3} w}{d x^{3}}-P \frac{d\left(w+w_{i}\right)}{d x} \\
M x=-E I a \frac{d^{3} \theta_{x}}{d x^{3}}+G I t \frac{d \theta_{x}}{d x}-M y \frac{d\left(v+v_{i}\right)}{d x}-\operatorname{Pr}_{0}^{2} \frac{d\left(\theta_{x}+\theta_{x i}\right)}{d x} \\
M y=-E I y \frac{d^{2} w}{d x^{2}} \\
M z=E I z \frac{d^{2} v}{d x^{2}} \\
B i=E I a \frac{d^{2} \theta_{x}}{d x^{2}}
\end{gathered}
$$

The relationship between forces and displacements (Figure 4), stiffness matrix is given by:

Axial (The shortening due to bowing effects is neglected):

$$
\left\{\begin{array}{l}
f_{x 1} \\
f_{x 2}
\end{array}\right\}=\left[\begin{array}{cc}
\frac{E A}{L} & \frac{-E A}{L} \\
\frac{-E A}{L} & \frac{E A}{L}
\end{array}\right]\left\{\begin{array}{l}
u_{1} \\
u_{2}
\end{array}\right\}+\left\{\begin{array}{l}
f_{e x 1} \\
f_{e x 2}
\end{array}\right\}
$$

Strong bending:

$$
\begin{aligned}
& \left\{\begin{array}{c}
f_{z 1} \\
M_{y 1} \\
f_{z 2} \\
M_{y 2}
\end{array}\right\}=\frac{k^{2} E I y}{2-2 c-k L s}\left[\begin{array}{cccc}
s k & c-1 & -s k & c-1 \\
c-1 & \frac{s-k L c}{k} & 1-c & \frac{k L-s}{k} \\
-s k & 1-c & s k & 1-c \\
c-1 & \frac{k L-s}{k} & 1-c & \frac{s-k L c}{k}
\end{array}\right]\left\{\begin{array}{c}
w_{1} \\
\theta_{y 1} \\
w_{2} \\
\theta_{y 2}
\end{array}\right\}+\left\{\begin{array}{c}
f_{e z 1} \\
M_{e y 1} \\
f_{e z 2} \\
M_{e y 2}
\end{array}\right\} \\
& c=\cos (k L) ; s=\operatorname{sen}(k L)
\end{aligned}
$$

Weak bending coupled with torsion:

$$
\left\{\begin{array}{c}
f_{y 1} \\
M_{x 1} \\
M_{z 1} \\
B i_{1} \\
f_{y 2} \\
M_{x 2} \\
M_{z 2} \\
B i_{2}
\end{array}\right\}=[A] \cdot[B]^{-1} \cdot\left\{\begin{array}{c}
v_{1} \\
\theta_{x 1} \\
\theta_{z 1} \\
\phi_{1} \\
v_{2} \\
\theta_{x 2} \\
\theta_{z 2} \\
\phi_{2}
\end{array}\right\}+\left\{\begin{array}{c}
f_{e y 1} \\
M_{e x 1} \\
M_{e z 1} \\
B i_{e 1} \\
f_{e y 2} \\
M_{e x 2} \\
M_{e z 2} \\
B i_{e 2}
\end{array}\right\}
$$




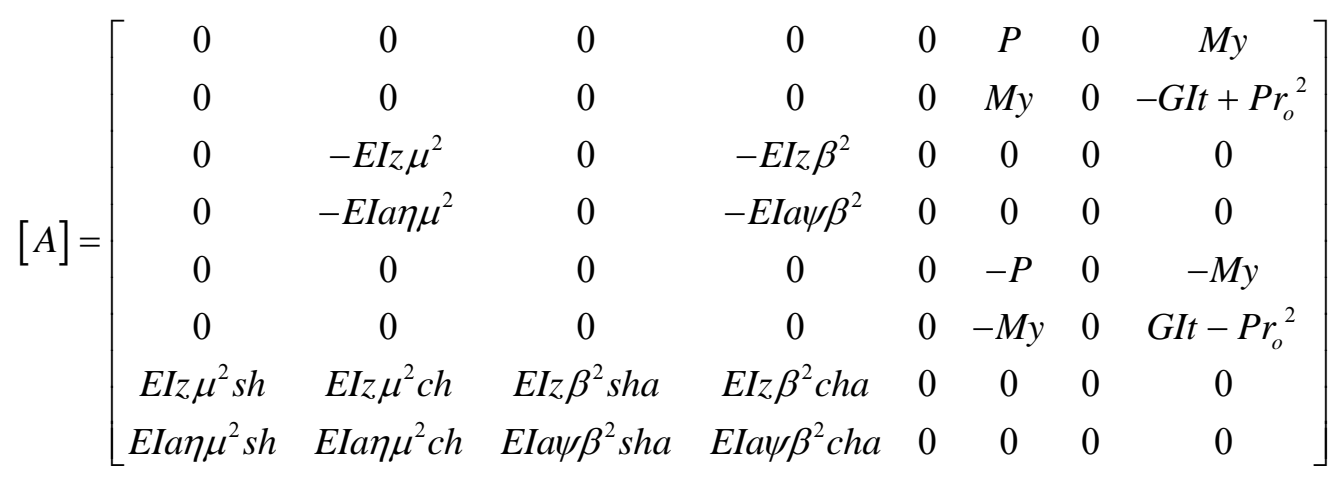

$$
[B]=\left[\begin{array}{cccccccc}
0 & 1 & 0 & 1 & 1 & 0 & 0 & 0 \\
0 & \eta & 0 & \psi & 0 & 0 & 1 & 0 \\
\mu & 0 & \beta & 0 & 0 & 1 & 0 & 0 \\
\mu \eta & 0 & \beta \psi & 0 & 0 & 0 & 0 & 1 \\
s h & c h & \text { sha } & \text { cha } & 1 & L & 0 & 0 \\
\eta s h & \eta c h & \psi s h a & \psi c h a & 0 & 0 & 1 & L \\
\mu c h & \mu s h & \beta c h a & \beta s h a & 0 & 1 & 0 & 0 \\
\mu \eta c h & \mu \eta s h & \beta \psi c h a & \beta \psi s h a & 0 & 0 & 0 & 1
\end{array}\right]
$$

$\operatorname{ch}=\cosh (\mu L) ; \operatorname{sh}=\operatorname{senh}(\mu L) ; \operatorname{ch} a=\cosh (\beta L) ; \operatorname{sh} a=\operatorname{senh}(\beta L)$
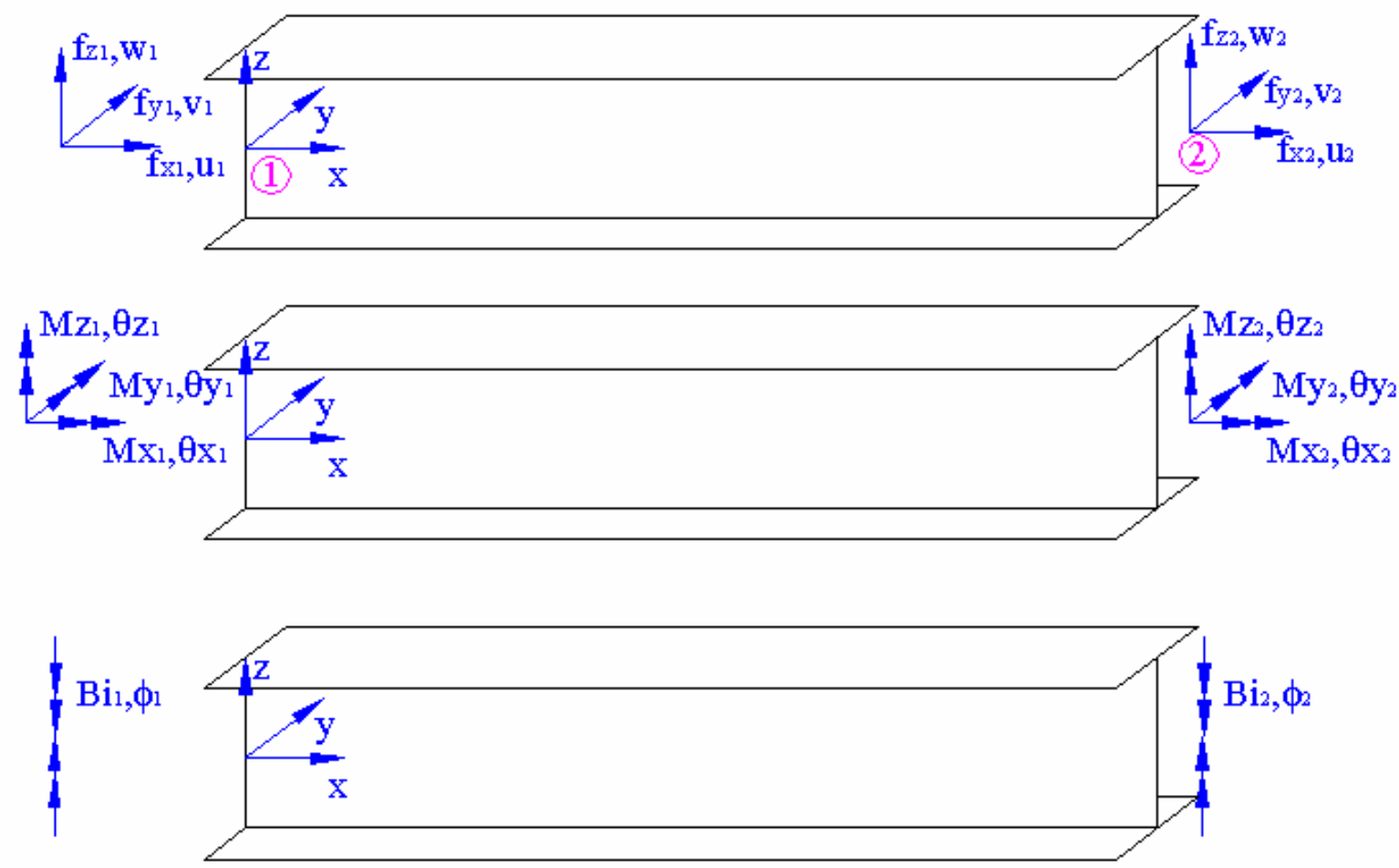

Figure 4. Forces and displacements

To apply the finite element method the first variation of the potential for a double symmetric section is used: 


$$
\begin{aligned}
& \delta V^{e}=\int\left(E A u_{p}^{\prime} u^{\prime}+E^{\prime} y w_{p}^{\prime \prime} w^{\prime \prime}+\operatorname{EIzw}_{p} v^{\prime \prime}+G_{T} \theta_{x p}{ }^{\prime} \theta_{x}{ }^{\prime}+\operatorname{EIa}_{x p} " \theta_{x}{ }^{\prime \prime}\right) d x-f_{x 1} u_{p 1}-f_{y 1} v_{p 1}-f_{z 1} w_{p 1} \\
& -f_{x 2} u_{p 2}-f_{y 2} v_{p 2}-f_{z 2} w_{p 2}-M_{x 1} \theta_{x p 1}-M_{y 1} \theta_{y p 1}-M_{z 1} \theta_{z p 1}-M_{x 2} \theta_{x p 2}-M_{y 2} \theta_{y p 2}-M_{z 2} \theta_{z p 2} \\
& -B i_{1} \phi_{p 1}-B i_{2} \phi_{p 2}-\int_{L}\left(p_{x} u_{p}+p_{y} v_{p}+p_{z} w_{p}+m_{x} \theta_{x p}\right) d x-\int M y\left[\left(v^{\prime}+v_{i}^{\prime}\right) \theta_{x p}{ }^{\prime}+\left(\theta_{x}{ }^{\prime}+\theta_{x i}{ }^{\prime}\right) v_{p}^{\prime}\right] d x \\
& -\int P\left(\left(v^{\prime}+v_{i}^{\prime}\right) v_{p}{ }^{\prime}+\left(w^{\prime}+w_{i}^{\prime}\right) w_{p}{ }^{\prime}+r O^{2}\left(\theta_{x}{ }^{\prime}+\theta_{x i}{ }^{\prime}\right) \theta_{x p}{ }^{\prime}\right) d x
\end{aligned}
$$

The equilibrium equations of the structure will be:

$$
\left(\left[K_{L}\right]+\left[K_{G}\right]\right)\left\{d_{N L}\right\}=\left\{F_{e x t}\right\}-\left[K_{G}\right]\left\{d_{i m p}\right\}
$$

\section{Simplified method to obtain the second order effects}

The orthogonality properties of the buckling modes $\left\{\phi_{\mathrm{vi}} ; \phi_{\mathrm{wi}} ; \phi_{\theta \mathrm{xi}}\right\}$ are for a general section, if $\mathrm{i} \neq$ $\mathrm{j}$ :

In a column, with primary axial forces $\{\mathrm{P}\}$ :

$$
\begin{gathered}
\int P\left(\phi_{v i}^{\prime} \phi_{v j}^{\prime}+\phi_{w i}^{\prime} \phi_{w j}^{\prime}+r o^{2} \phi_{\theta_{x}}^{\prime} \phi_{\theta_{x j}}^{\prime}+2 z c \phi_{v i}^{\prime} \phi_{\theta x j}^{\prime}-2 y c \phi_{w i}^{\prime} \phi_{\theta x j}^{\prime}\right) d x=\left\{\phi_{j}\right\}^{T}\left[K_{G N}\right]\left\{\phi_{i}\right\}=0 \\
\int_{L}\left[E I_{y} \phi_{w i}^{\prime \prime} \phi_{w j}^{\prime \prime}+E I_{z} \phi_{v i}^{\prime \prime} \phi_{v j}^{\prime \prime}+G I t \phi_{\theta x i}^{\prime} \phi_{\theta x j}^{\prime}+E I_{a} \phi_{\theta x i}^{\prime \prime} \phi_{\theta x j}^{\prime \prime}\right] d x=\left\{\phi_{j}\right\}^{T}\left[K_{L}\right]\left\{\phi_{i}\right\}=0 r o^{2}=\frac{I y+I z}{A}+y c^{2}+z c^{2}
\end{gathered}
$$

In a beam, with primary strong bending $\{\mathrm{My}\}$ :

$$
\begin{gathered}
\int_{L}\left[2 M y\left(\beta y \phi_{\theta x j}^{\prime} \phi_{\theta x i}^{\prime}+\phi_{v i}^{\prime \prime} \phi_{\theta x j}\right)\right] d x=\left\{\phi_{j}\right\}^{T}\left[K_{G M}\right]\left\{\phi_{i}\right\}=0 \\
\int_{L}\left[E I_{z} \phi_{v i}^{\prime \prime} \phi_{v j}^{\prime \prime}+G I t \phi_{\theta x i}^{\prime} \phi_{\theta x j}^{\prime}+E I_{a} \phi_{\theta x i}^{\prime \prime} \phi_{\theta x j}^{\prime \prime}\right] d x=\left\{\phi_{j}\right\}^{T}\left[K_{L}\right]\left\{\phi_{i}\right\}=0 \\
\beta y=\frac{1}{2 \cdot I y} \iint_{A} z\left(y^{2}+z^{2}\right) d A-z c
\end{gathered}
$$

In a beam-column, with primary axial and strong bending $\{\mathrm{P}, \mathrm{My}\}$ :

$$
\begin{aligned}
\int & {\left[2 M y\left(\beta y \phi_{\theta x j}^{\prime} \phi_{\theta x i}^{\prime}+\phi_{v i}^{? \prime} \phi_{\theta x j}\right)+P\left(\phi_{v i}^{\prime} \phi_{v j}^{\prime}+\phi_{w i}^{\prime} \phi_{w j}^{\prime}+r O^{2} \phi_{\theta_{x}}^{\prime} \phi_{\theta_{x} j}^{\prime}+2 z c \phi_{v i}^{\prime} \phi_{\theta x j}^{\prime}-2 y c \phi_{w i}^{\prime} \phi_{\theta x j}^{\prime}\right)\right] d x=} \\
=\left\{\phi_{j}\right\}^{T}\left[K_{G N M}\right]\left\{\phi_{i}\right\}=0 & \\
& \int_{L}\left[E I_{y} \phi_{w i}^{\prime \prime} \phi_{w j}^{\prime \prime}+E I_{z} \phi_{v i}^{\prime \prime} \phi_{v j}^{\prime \prime}+G I t \phi_{\theta x i}^{\prime} \phi_{\theta x j}^{\prime}+E I_{a} \phi_{\theta x i}^{\prime \prime} \phi_{\theta x j}^{\prime \prime}\right] d x=\left\{\phi_{j}\right\}^{T}\left[K_{L}\right]\left\{\phi_{i}\right\}=0
\end{aligned}
$$

where $\beta y=\frac{1}{2 I y} \iint_{A} z\left(y^{2}+z^{2}\right) d A-z c$, yc, zc are the shear center coordinates.

The nonlinear displacements can be expressed using these properties as:

$$
\begin{gathered}
\left\{d_{N L}\right\}=\left\{d_{L}\right\}+\sum_{j=1}^{n} \frac{a_{j}}{\left(\mu_{j}-1\right)}\left\{\phi_{j}\right\}+\frac{F_{\text {actgeo }}}{\left(\mu_{1}-1\right)}\left\{\phi_{1}\right\} \approx\{d\}+\frac{a_{1}+F_{\text {actgeo }}}{\left(\mu_{1}-1\right)}\left\{\phi_{1}\right\} \\
\left\{a_{j}\right\}=\frac{\left\{\phi_{j}\right\}^{T}\left\{F_{\text {ext }}\right\}}{\left\{\phi_{j}\right\}^{T}\left[K_{L}\right]\left\{\phi_{j}\right\}}
\end{gathered}
$$

where $\mathrm{F}_{\text {actgeo }}$ define the magnitude of the imperfection and the coefficient $\mathrm{a}_{\mathrm{j}}$ gives the expression of the linear displacements $\left\{\mathrm{d}_{\mathrm{L}}\right\}$ as a linear combination of the buckling modes. 
In a structure with primary bending moments and axial forces that may induce buckling, the nonlinear displacements can be obtained as:

$$
\begin{aligned}
& \left\{d_{N L}\right\}=\left\{d_{L}\right\}+\frac{a_{1 M N}}{\left(\mu_{1 M N}-1\right)}\left\{\phi_{1 M N}\right\}+\frac{F_{\text {actgeo }}}{\left(\mu_{1 M N}-1\right)}\left\{\phi_{1 M N}\right\} \\
& \left\{a_{1 M N}\right\}=\frac{\int\left[E I_{y} w^{\prime \prime} \phi_{w 1}^{\prime \prime}+E I_{z} v^{\prime \prime} \phi_{v 1}^{\prime \prime}+G I t \theta_{x}^{\prime} \phi_{\theta x 1}^{\prime}+E I_{a} \theta_{x}^{\prime \prime} \phi_{\theta x 1}^{\prime \prime}\right] d x}{\int\left[E I_{y} \phi_{w 1}^{\prime \prime}{ }^{2}+E I_{z} \phi_{v 1}^{\prime \prime}+G I t \phi_{\theta x 1}^{\prime}{ }^{2}+E I_{a} \phi_{\theta x i}^{\prime \prime}\right] d x}=\frac{\left\{\phi_{1 M N}\right\}^{T}\left\{F_{e x t}\right\}}{\left\{\phi_{1 M N}\right\}^{T}\left[K_{L}\right]\left\{\phi_{1 M N}\right\}}
\end{aligned}
$$

The nonlinear displacements can be expressed in a simplified way, consistently with the Eurocode where an imperfection is defined for axial effects $\mathrm{F}_{\text {actgeoN }}$ and for strong bending (implicitly through $\left.\chi_{\mathrm{LT}}\right)$ effects $\mathrm{F}_{\text {actgeoM, }}$ as:

$$
\left\{d_{N L}\right\} \approx\left\{d_{L}\right\}+\frac{a_{1 N}}{\left(\mu_{1 N}-1\right)}\left\{\phi_{1 N}\right\}+\frac{F_{\text {actgeoN }}}{\left(\mu_{1 N}-1\right)}\left\{\phi_{1 N}\right\}+\frac{a_{1 M}}{\left(\mu_{1 M}-1\right)}\left\{\phi_{1 M}\right\}+\frac{F_{\text {actgeoM }}}{\left(\mu_{1 M}-1\right)}\left\{\phi_{1 M}\right\}
$$

where the nonlinear displacements $\left\{\mathrm{d}_{\mathrm{NL}}\right\}$ are the linear $\left\{\mathrm{d}_{\mathrm{L}}\right\}$ plus the secondary effects due to the imperfection $\frac{F_{\text {actgeoN }}}{\left(\mu_{1 N}-1\right)}\left\{\phi_{1 N}\right\}$ and second order effects $\frac{a_{1 N}}{\left(\mu_{1 N}-1\right)}\left\{\phi_{1 N}\right\}$ due to axial forces, plus the secondary effects due to the imperfection $\frac{F_{\text {actgeom }}}{\left(\mu_{1 M}-1\right)}\left\{\phi_{1 M}\right\}$ and second order effects $\frac{a_{1 M}}{\left(\mu_{1 M}-1\right)}\left\{\phi_{1 M}\right\}$ (this effect is not considered by the current standards) due to strong bending moments.

So if we want to study with the simplified proposal the example in Figure 5 with primary axial and strong bending moments, 3 key analysis must be performed a linear, initial instability analysis with axial forces and a initial stability analysis with strong bending moments.

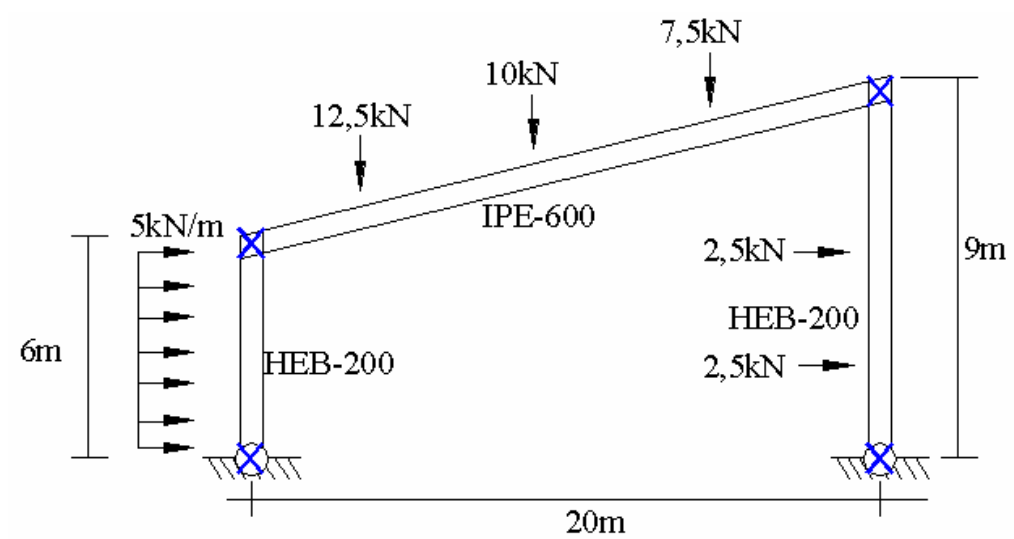

Figure 5.1. Example with axial and bending moment

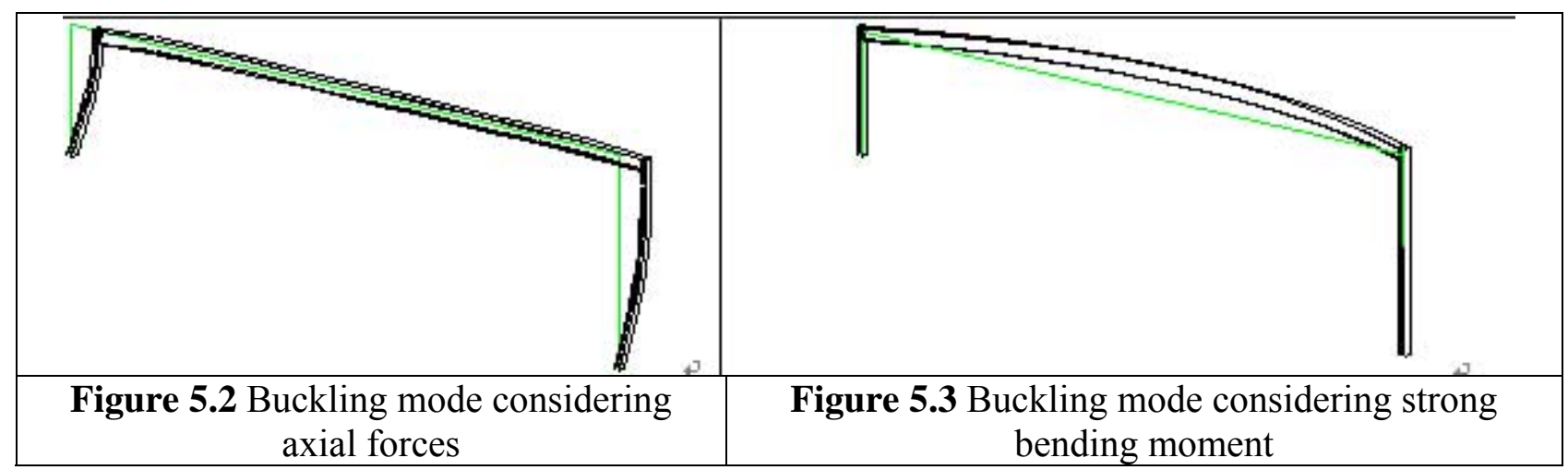




\section{Simplified method to obtain the geometric equivalent imperfection}

To generalize Dutheil's method, the collapse loads obtained by the current standards with only primary axial forces or bending moment are accepted.

The scaling factor of the geometric imperfection is obtained by equating the collapse load obtained with the proposed method considering only primary axial (Factgeo ${ }_{\mathrm{N}}$ ) forces or bending moment (Factgeo $\mathrm{M}_{\mathrm{M}}$ ) with the one's obtained by the current standards (Figure 6).

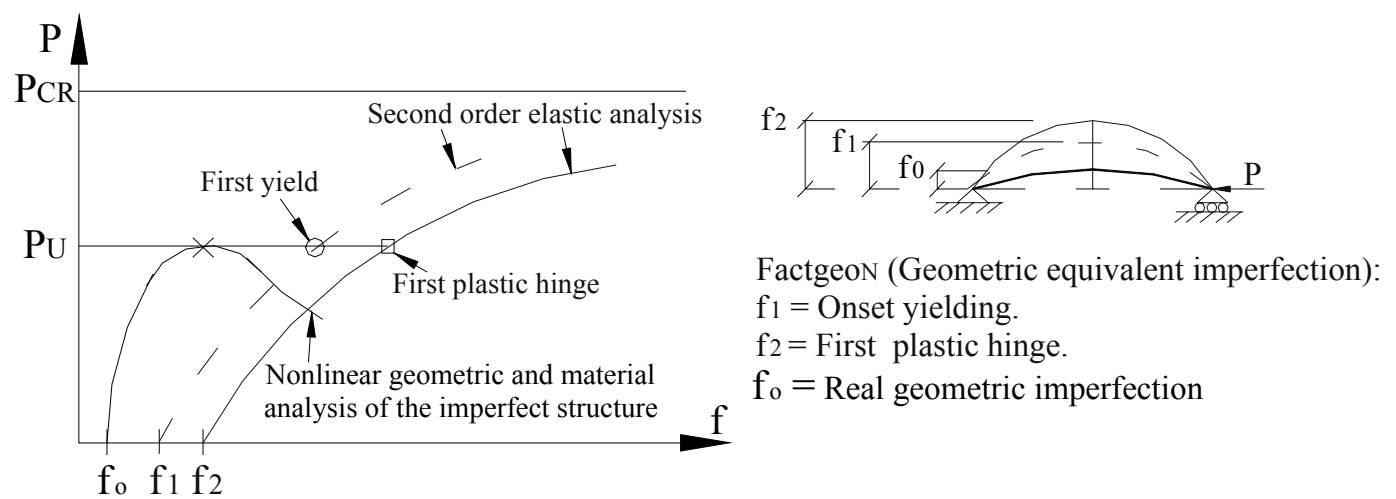

Figure 6. Calculate the geometric equivalent imperfection

So two imperfections are obtained:

A- considering only primary axial forces $\left(\right.$ Factgeo $\left._{N}\right)$.

B- considering only primary strong bending moments $\left(\right.$ Factgeo $\left._{M}\right)$.

\section{Case A. Only axial forces (Fiqure 7):}

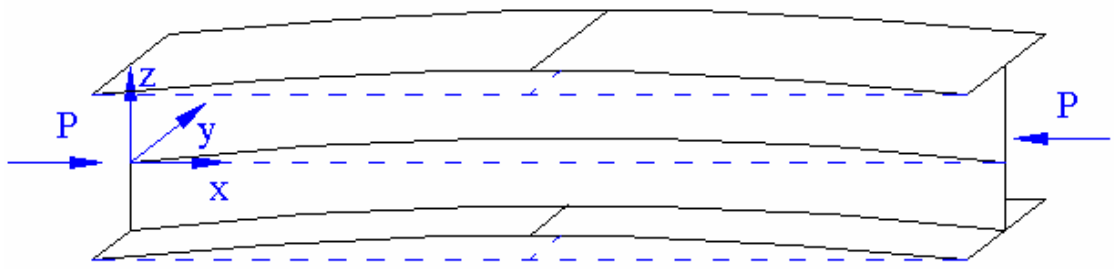

Figure 7. Considering only axial force

From the initial instability analysis with only axial forces $\left(\left[K_{L}\right]+\mu_{1 N}\left[K_{G N}\right]\right)\left\{\phi_{1 N}\right\}=\{0\}$, the first buckling load $\mu_{1 N}=\mu_{c r \text { 越ca }}$ and buckling mode $\left\{\phi_{1 N}\right\}$ are obtained.

To calculate the collapse load $\mu_{\text {collapse } N}$ considering only the axial internal forces, the collapse load of each column are obtained according to:

The Spanish standard (EA-95) $P_{U}^{K B}=\frac{A^{K B} \sigma_{e}}{\omega^{K B}}$

The Eurocode 3 as $P_{U}^{K B}=\frac{A^{K B} \sigma_{e} \chi^{K B}}{\gamma_{m 1}}$ 
where the superscript $\mathrm{KB}$ denotes the column number $\mathrm{KB}$, and $\omega, \chi$ depend on the normalized slenderness $\bar{\lambda}^{K B}=\sqrt{\frac{A \sigma_{e}}{\mu_{1 N} P_{K B}}}$, see Buckling curve (Figure 8).

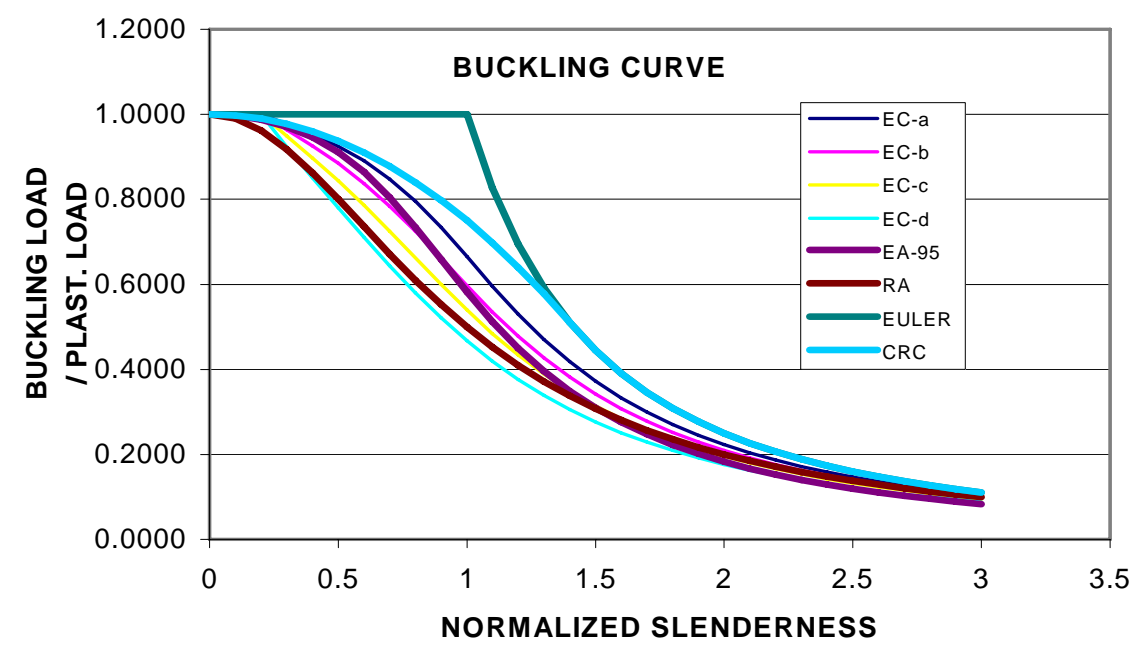

Figure 8. Buckling curves

Hence $\mu_{\text {collapse_N }}^{K B}=\frac{A^{K B} \sigma_{e}}{P_{K B} \varpi^{K B}} ; \mu_{\text {collapse } \_}^{K B}=\frac{A^{K B} \sigma_{e} \chi^{K B}}{P_{K B} \gamma_{m 1}}$

And the collapse load of the structure is $\mu_{\text {collapse } N}=\operatorname{minimum}\left\{\mu_{\text {collapse_N }}^{1}, \ldots, \mu_{\text {collapse } N}^{N B}\right\}$

The initial stability analysis gives the buckling modes and the secondary internal forces developed when the structure has an imperfection given by the first buckling mode. This can be calculated at the collapse load of the structures $\mu_{\text {collapse }_{N}}$ as:

$$
\begin{aligned}
& \text { Mys }=-E I y \frac{F_{a c t g e o N}}{\gamma-1} \frac{d^{2} \phi_{w}}{d x^{2}} \\
& M z s=E I z \frac{F_{a c t g e o N}}{\gamma-1} \frac{d^{2} \phi_{v}}{d x^{2}} \\
& \text { Bis }=E I a \frac{F_{\text {actgeoN }}}{\gamma-1} \frac{d^{2} \phi_{\theta x}}{d x^{2}} \\
& \gamma=\frac{\mu_{\text {cr 䟁ica } N}}{\mu_{\text {collapse_N }}}
\end{aligned}
$$

The geometric imperfection $\left(\right.$ Factgeo $\left._{N}\right)$ is obtained imposing the collapse condition for $\mu_{\text {collapse_N }}$, of the structure with the primary $\{\mathrm{N}\}$ and secondary $\left\{\mathrm{M}_{\mathrm{ZS}}, \mathrm{M}_{\mathrm{YS}}, \mathrm{Bi}_{\mathrm{S}}\right\}$ internal forces calculated:

$$
\frac{N_{K B} \cdot \mu_{\text {collapse }_{2} N}}{N_{\text {el }}^{K B}}+\frac{M_{Z S}^{K B}}{M_{\text {zel }}^{K B}}+\frac{M_{Y S}^{K B}}{M_{\text {yel }}^{K B}}+\frac{B i_{s}^{K B}}{B i_{e l}^{K B}} \leq 1
$$

In case that the section is class 2 this will be given by the formation of the first plastic hinge (a more accurate result can be obtained using the appropriate cross section interaction formulae):

$$
\frac{N_{K B} \cdot \mu_{\text {collapse_N } N}}{N_{p l}^{K B}}+\frac{M_{Z S}^{K B}}{M_{z p l}^{K B}}+\frac{M_{Y S}^{K B}}{M_{y p l}^{K B}}+\frac{B i_{s}^{K B}}{B i_{p l}^{K B}} \leq 1
$$


Example $\mathrm{n}^{\circ} 1$ : A simply supported beam-column with out of plane buckling restrained is studied, geometry definition and loading in Figure 9.

$$
\begin{gathered}
\left\{d_{N L}\right\} \approx\left\{d_{L}\right\}+\frac{a_{1 N}}{\left(\mu_{1 N}-1\right)}\left\{\phi_{1 N}\right\}+\frac{F_{\text {actgeoN }}}{\left(\mu_{1 N}-1\right)}\left\{\phi_{1 N}\right\} \\
\left\{\phi_{1 N}\right\}=\left\{\phi_{v}\right\}=\left\{\sin \left(\frac{\pi \cdot x}{L}\right)\right\} ; F_{\text {actgeoN }}=\frac{\sigma_{e}(1-\chi) W z}{\operatorname{Pcr}\left(\frac{1}{\gamma-1}\right)}
\end{gathered}
$$

Hence

$$
v \approx \frac{M}{2 E I z} x(L-x)+\left(\frac{4 M L^{2}}{\pi^{3} E I z}+\frac{\sigma_{e}(1-\chi) W z}{\operatorname{Pcr}\left(\frac{1}{\gamma-1}\right)}\right) \frac{\operatorname{sen}\left(\frac{\pi x}{L}\right)}{\left(\mu_{1}-1\right)}
$$

where $P c r=\frac{\pi^{2} E I z}{L^{2}}$

The "exact" solution is:

$$
v=\frac{M}{P}\left[\left(\frac{\operatorname{sen}(k x)}{\tan (k L)}-\cos (k x)-\frac{x}{L}+1\right)-\left(\frac{\operatorname{sen}(k x)}{\operatorname{sen}(k L)}-\frac{x}{L}\right)\right]+\frac{F_{a c t g e o N}}{\left(\mu_{1 N}-1\right)}\left\{\phi_{1 N}\right\} ; k=\sqrt{\frac{P}{E I z}}
$$

In Figure 9 can be appreciated that the internal bending moments are the primary ones plus the amplification of this due to the axial force plus the ones due to the imperfection.
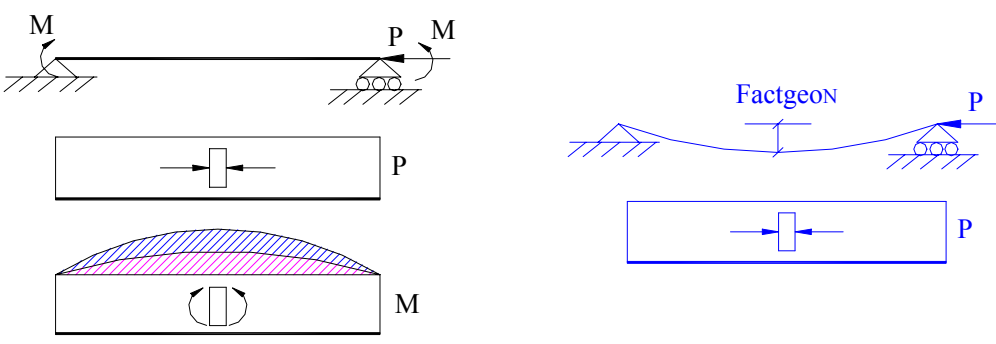

Figure 9. Example 1

Case B. Only strong bending moment (Figure 10):

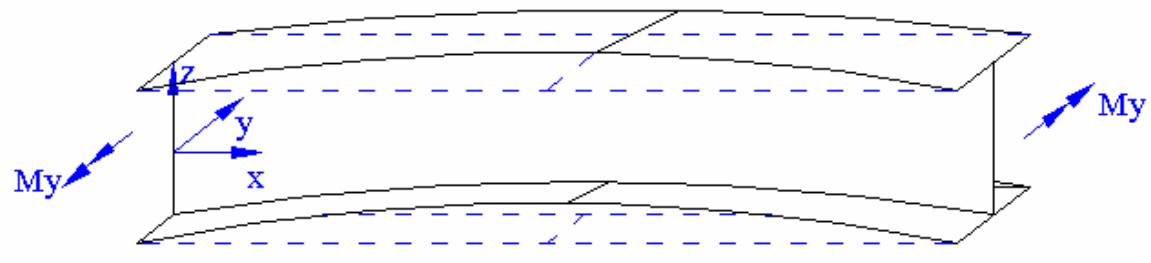

Figure 10. Considering only strong bending moments.

From the initial instability analysis with only strong bending moments $\left(\left[K_{L}\right]+\mu_{1 M}\left[K_{G M}\right]\right)\left\{\phi_{1 M}\right\}=\{0\}$, the first buckling load $\mu_{1 M}=\mu_{\text {cr 题ca }{ }_{M} \text { M }}$ and buckling mode $\left\{\phi_{1 \mathrm{M}}\right\}$ are obtained. 
To calculate the collapse load considering only the bending moments $\mu_{\text {collapse_M }}$, the collapse load of each beam are obtained according to:

The Eurocode 3 as $M_{U}^{K B}=\frac{W y^{K B} \sigma_{e} \chi_{L T}{ }^{K B}}{\gamma_{m 1}}$

where $\chi_{\mathrm{LT}}$ depend on $\bar{\lambda}^{K B}=\sqrt{\frac{\gamma_{m 1}}{\mu_{1 M} M \sigma_{e}}}$

Hence $\mu_{\text {collapse_}{ }_{-}{ }^{K B}}=\frac{W y^{K B} \sigma_{e} \chi_{L T}{ }^{K B}}{M y_{K B} \gamma_{m 1}}$

And the collapse load of the structure is $\mu_{\text {collapse_} \_}=\operatorname{minimum}\left\{\mu_{\text {collapse_}}^{1}{ }_{-}, \ldots, \mu_{\text {collapse_}}^{N B}\right\}$

The initial stability analysis gives the buckling modes and the secondary internal forces developed when the structure has an imperfection given by the first buckling mode. These can be calculated at the collapse load of the structures $\mu_{\text {collapse_m }}$ as:

$$
\begin{gathered}
\text { Mzs }=E I z \frac{F_{\text {actgeo } M}}{\gamma-1} \frac{d^{2} \phi_{v}}{d x^{2}} \\
\text { Bis }=E I a \frac{F_{\text {actgeo } M}}{\gamma-1} \frac{d^{2} \phi_{\theta x}}{d x^{2}} \\
\gamma=\frac{\mu_{\text {cr静ca_M } M}}{\mu_{\text {collapse_M }}}
\end{gathered}
$$

The geometric imperfection (Factgeo $)_{M}$ is obtained imposing the collapse condition of the structure with the primary $\left\{\mathrm{M}_{\mathrm{Y}}\right\}$ and secondary $\left\{\mathrm{M}_{\mathrm{ZS}}, \mathrm{Bi}_{\mathrm{S}}\right\}$ internal forces:

$$
\frac{M_{Y}^{K B} \mu_{\text {collapse_M }}}{M_{\text {yel }}^{K B}}+\frac{M_{Z S}^{K B}}{M_{z e l}^{K B}}+\frac{B i_{S}^{K B}}{B i_{e l}^{K B}} \leq 1
$$

In case that the section is class 2 this will be given by the formation of the first plastic hinge (a more accurate result can be obtained using the appropriate cross section interaction formulae):

$$
\frac{M_{Y}^{K B} \mu_{\text {collapse } \_} M}{M_{y p l}^{K B}}+\frac{M_{Z S}^{K B}}{M_{z p l}^{K B}}+\frac{B i_{s}^{K B}}{B i_{p l}^{K B}} \leq 1
$$

Example $\mathrm{n}^{\mathrm{0}} 2$ : A simply supported beam under strong bending moment and a sinusoidal distributed load $p_{y}$ is studied .Geometry definition and loading in Fig. 11.

$$
\begin{aligned}
& \left\{d_{N L}\right\} \approx\left\{d_{L}\right\}+\frac{a_{1 M}}{\left(\mu_{1 M}-1\right)}\left\{\phi_{1 M}\right\}+\frac{F_{\text {actgeo } M}}{\left(\mu_{1 M}-1\right)}\left\{\phi_{1 M}\right\} \\
& \left\{\phi_{1 M}\right\}=\left\{\begin{array}{c}
\phi_{v} \\
\phi_{\theta x}
\end{array}\right\}=\left\{\begin{array}{c}
\sin \left(\frac{\pi x}{L}\right) \\
\frac{\pi^{2} E I z}{L^{2}} \operatorname{Mcr} \sin \left(\frac{\pi x}{L}\right)
\end{array}\right\} ; F_{\text {actgeo M }}=\frac{\sigma_{e}\left(1-\chi_{L T}\right)(\gamma-1)}{\gamma_{m 1} P z\left[\frac{1}{W_{\text {zel }}}+\frac{E I a \pi^{2}}{W_{\text {Biel }} M c r L^{2}}\right]} \\
& a_{1 M}=\frac{\int\left(E I z v " \phi_{v 1}{ }^{\prime \prime}+\operatorname{GIt}_{x}{ }^{\prime} \phi_{\theta \times 1}{ }^{\prime}+E I a \theta_{x}{ }^{\prime \prime} \phi_{\theta \times 1}{ }^{\prime \prime}\right) \cdot d x}{\int\left(E I z\left(\phi_{v 1}\right)^{2}+\operatorname{GIt}\left(\phi_{\theta \times 1}\right)^{2}+\operatorname{EIa}\left(\phi_{\theta \times 1}\right)^{2}\right) \cdot d x}=\frac{\frac{\pi^{2} M z o}{2 L}}{\frac{\pi^{4} E I z}{L^{3}}}=\frac{1}{2} \frac{L^{2} M z o}{\pi^{2} E I z}
\end{aligned}
$$


Hence:

$$
\left\{\begin{array}{c}
v \\
\theta_{x}
\end{array}\right\}=\frac{M z o}{P z} \operatorname{sen}\left(\frac{\pi x}{L}\right)\left[\left\{\begin{array}{l}
1 \\
0
\end{array}\right\}+\left(\frac{1}{2\left(\mu_{1}-1\right)}+\frac{\frac{\sigma_{e}\left(1-\chi_{L T}\right)(\gamma-1)}{\gamma_{m 1} M z o\left[\frac{1}{W_{z e l}}+\frac{E I a \pi^{2}}{W_{\text {Biel }} M c r L^{2}}\right]}}{\left(\mu_{1}-1\right)}\right]\left\{\begin{array}{c}
1 \\
P z \\
\frac{P z}{M c r}
\end{array}\right\}\right]
$$

where $M c r=\frac{\pi^{2} E I z}{L^{2}} \sqrt{\left(\frac{I a}{I z}+\frac{L^{2} G I t}{\pi^{2} E I z}\right)} ; P z=\frac{\pi^{2} E I z}{L^{2}}$

The "exact" solution is:

$$
\left\{\begin{array}{c}
v \\
\theta_{x}
\end{array}\right\}=\frac{M z_{o} \sin \left(\frac{\pi x}{L}\right)}{M c r^{2}-M y^{2}}\left\{\left(\begin{array}{c}
\left.G I t+\frac{\pi^{2} E I a}{L^{2}}\right) \\
M y
\end{array}\right\}+\frac{F_{\text {actgeo } M}}{\left(\mu_{1 M}-1\right)}\left\{\phi_{1 M}\right\}\right.
$$

In Figure 11 can be appreciated that the internal weak bending moments are the primary ones plus the amplification of this due to the strong bending moments plus the ones due to the imperfection. Secondary bimoments and torsion appear. In the current standards only the effects of the imperfection are considered.

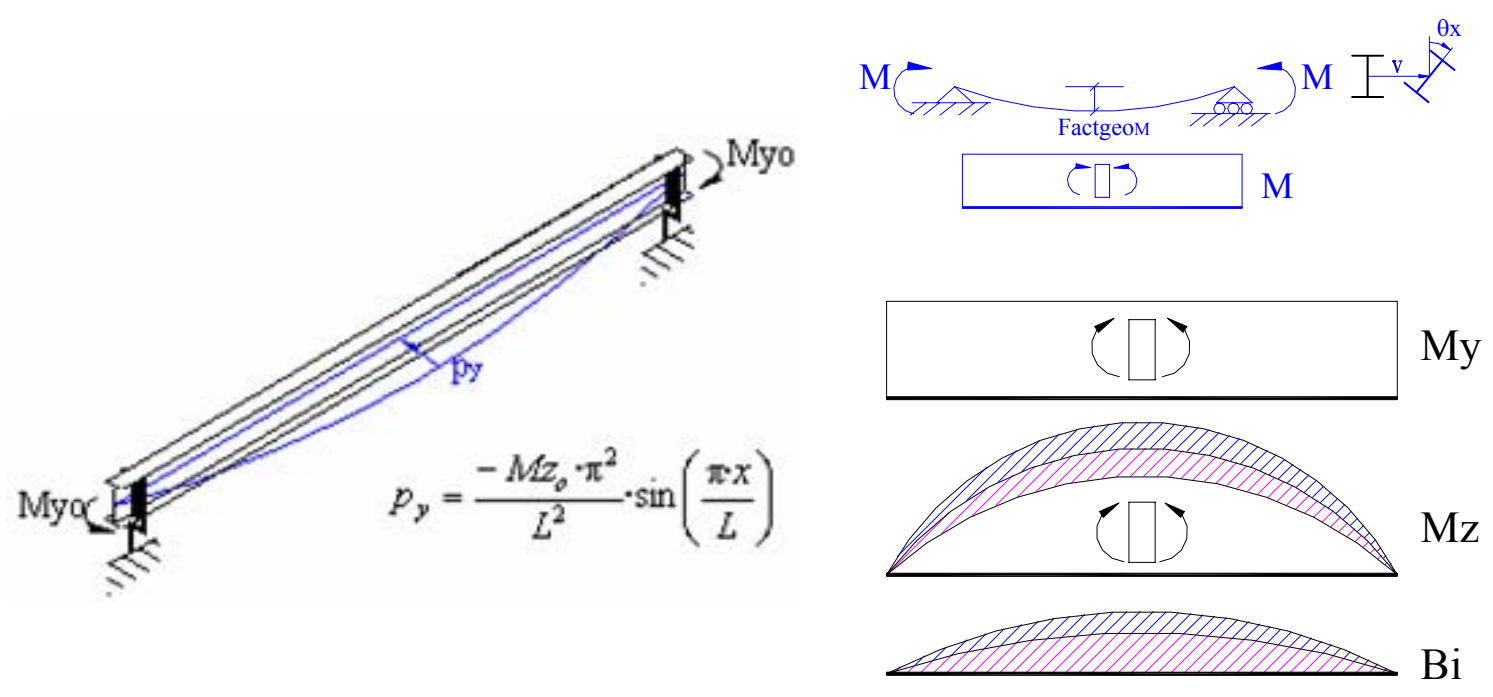

Figure 11. Example 2

$$
\frac{M_{Z}^{K B}+M_{Z S M}^{K B}}{M_{z e l}^{K B}}+\frac{M_{Y}^{K B}}{M_{y e l}^{K B}}+\frac{B i^{K B}+B i_{S M}^{K B}}{B i_{e l}^{K B}} \leq 1
$$




\section{DESIGN IMPLEMENTATION}

The implementation of this method is simple as it can be seen in the flow diagram of Figure 12. The steps followed are the described in section $\mathrm{n}^{\circ} 2$.

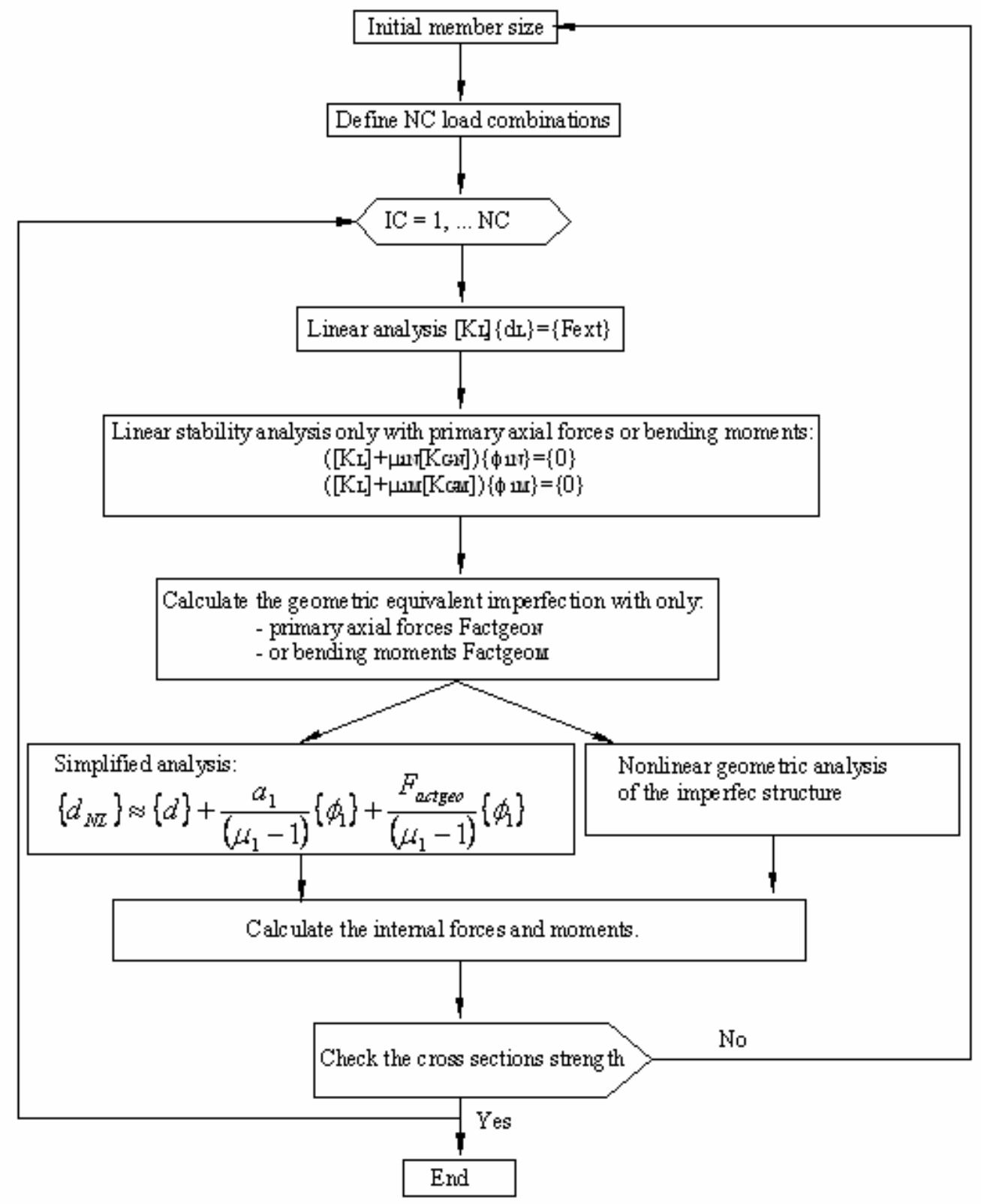

Figure 12. Design implementation

If the simplified method is chosen only the cross section strength check has to be made. For Class 3 sections:

$$
\frac{N_{K B}}{N_{e l}^{K B}}+\frac{M_{Z}^{K B}+M_{Z S N}^{K B}+M_{Z S M}^{K B}}{M_{z e l}^{K B}}+\frac{M_{Y}^{K B}+M_{Y S N}^{K B}}{M_{y e l}^{K B}}+\frac{B i^{K B}+B i_{S N}^{K B}+B i_{S M}^{K B}}{B i_{e l}^{K B}} \leq 1
$$

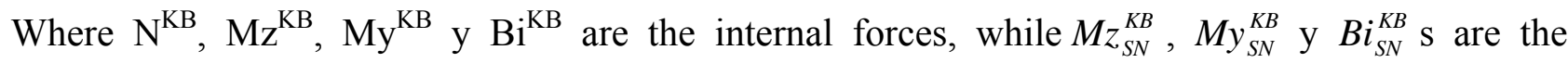
secondary effects due to the imperfection and second order effects due to axial forces. $M z_{S M}^{K B} \mathrm{y}$ $B i_{S M}^{K B}$ are the secondary effects due to the imperfection and second order effects due to strong bending moments. 


\section{EXAMPLES}

Several examples are presented to clarify some of the ideas behind the proposed methodology, in first place the geometric imperfection obtained according to 2.3 are compared with the one's obtained with current standards, in second place the second order effects associated to the buckling modes are plotted for a 2 span beam, at last the results for pitched roof frames are summarized.

\section{Geometric equivalent imperfection proposal vs Eurocode 3}

\subsubsection{Steel frames}

\subsection{1-A One story frame}

The purpose of this example is to compare the proposed geometric imperfection (Figures 13 and 14) in a one story frame with the EC-3 proposal (Figure 15) $\phi=k_{c} k_{s} \phi_{0}$ where $\phi_{1}=\frac{1}{200}$. The columns are HEB-200 and the beam is IPE-400.
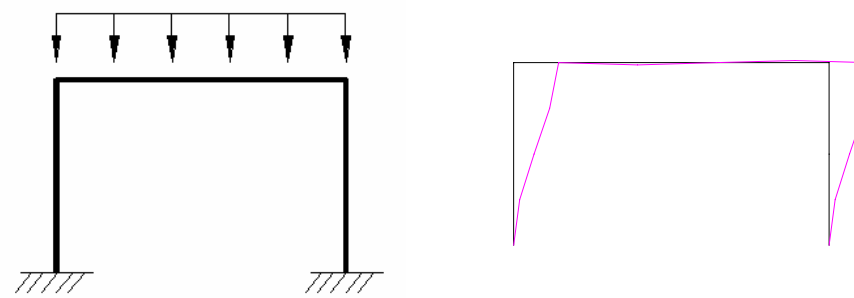

Figure 13. Loading, geometry and buckling mode. Fixed base
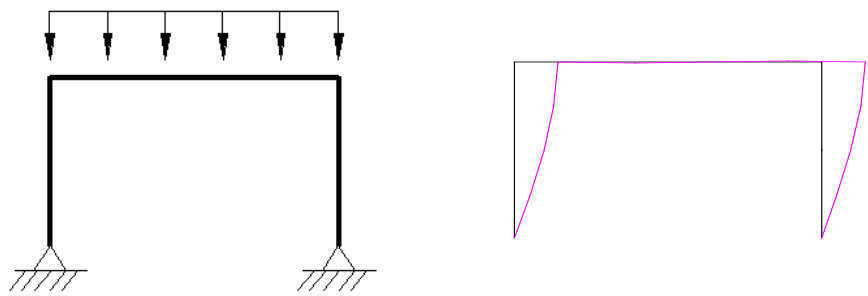

Figure 14. Loading, geometry and buckling mode. Pinned base

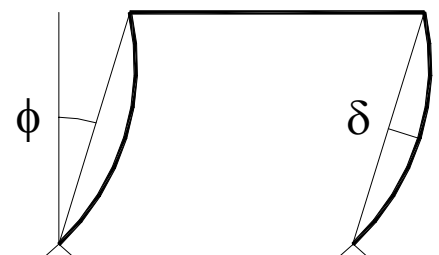

Figure 15. Geometric imperfection according to Eurocode

As can be seen for fixed column (Figure 13) there is a qualitative (shape) and quantitative difference $\phi_{\mathrm{EC}-3}=1 / 200$ and $\phi_{\mathrm{PROPOSAL}}=1 / 370$. While for pinned based column (Figure 14) there is only a small quantitaive difference $\phi_{\mathrm{EC}-3}=1 / 200$ and $\phi_{\mathrm{PROPOSAL}}=1 / 160$. 
The same conclusions than for a one story are obtained. As can be seen for fixed column (Figure 16) there is a qualitative and quantitative difference with eurocode's proposal. While for pinned based column (Figure 17) there is a small qualitative difference.

According to the EC-3 two imperfection patterns can be used (Figure 18), it can be shown that pattern $\mathrm{A}$ is worst as it is close to the first buckling mode.

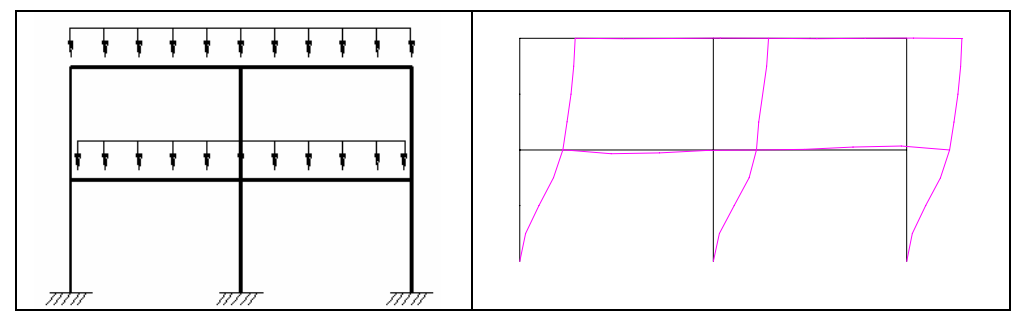

Figure 16. Loading, geometry and buckling mode. Fixed base

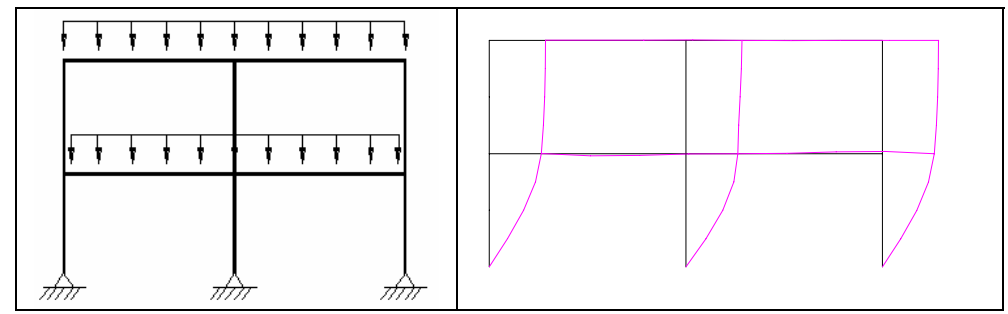

Figure 17. Loading, geometry and buckling mode. Pinned base

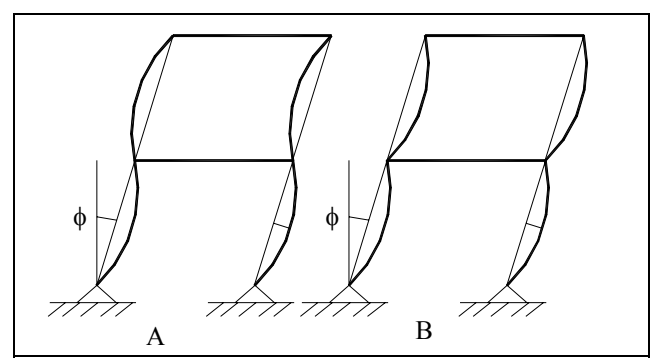

Figure 18. Two posible imperfection patterns

\subsection{1-C $\quad$ Vogel 2 frame (Figure 19):}

For this frame the geometric equivalent imperfection are also compared.

According to Eurocode the inter-storey drift imperfection is given by:

$\phi=k_{c} k_{s} \phi_{0}$

$\phi_{1}=\ldots=\phi_{6}=\sqrt{0.5+\frac{1}{3}} \sqrt{0.2+\frac{1}{6}} \frac{1}{200}=0.9 \cdot 0.6 \cdot \frac{1}{200}=\frac{1}{362}$

According to the proposal the inter-storey drift imperfection is given by:

$\phi_{1}=\frac{0.009}{3.75}=\frac{1}{416} ; \phi_{2}=\frac{(0.028-0.009)}{3.75}=\frac{1}{200} ; \phi_{3}=\frac{(0.05-0.028)}{3.75}=\frac{1}{172} ; \phi_{4}=\frac{(0.066-0.05)}{3.75}=\frac{1}{238} ;$

$\phi_{5}=\frac{(0.08-0.066)}{3.75}=\frac{1}{268} ; \phi_{6}=\frac{(0.083-0.08)}{3.75}=\frac{1}{1250}$ 
There is an important qualitative difference, while the eurocode give the same interstorey drift imperfection to all the storeys, in the proposal this change (like in the buckling mode).

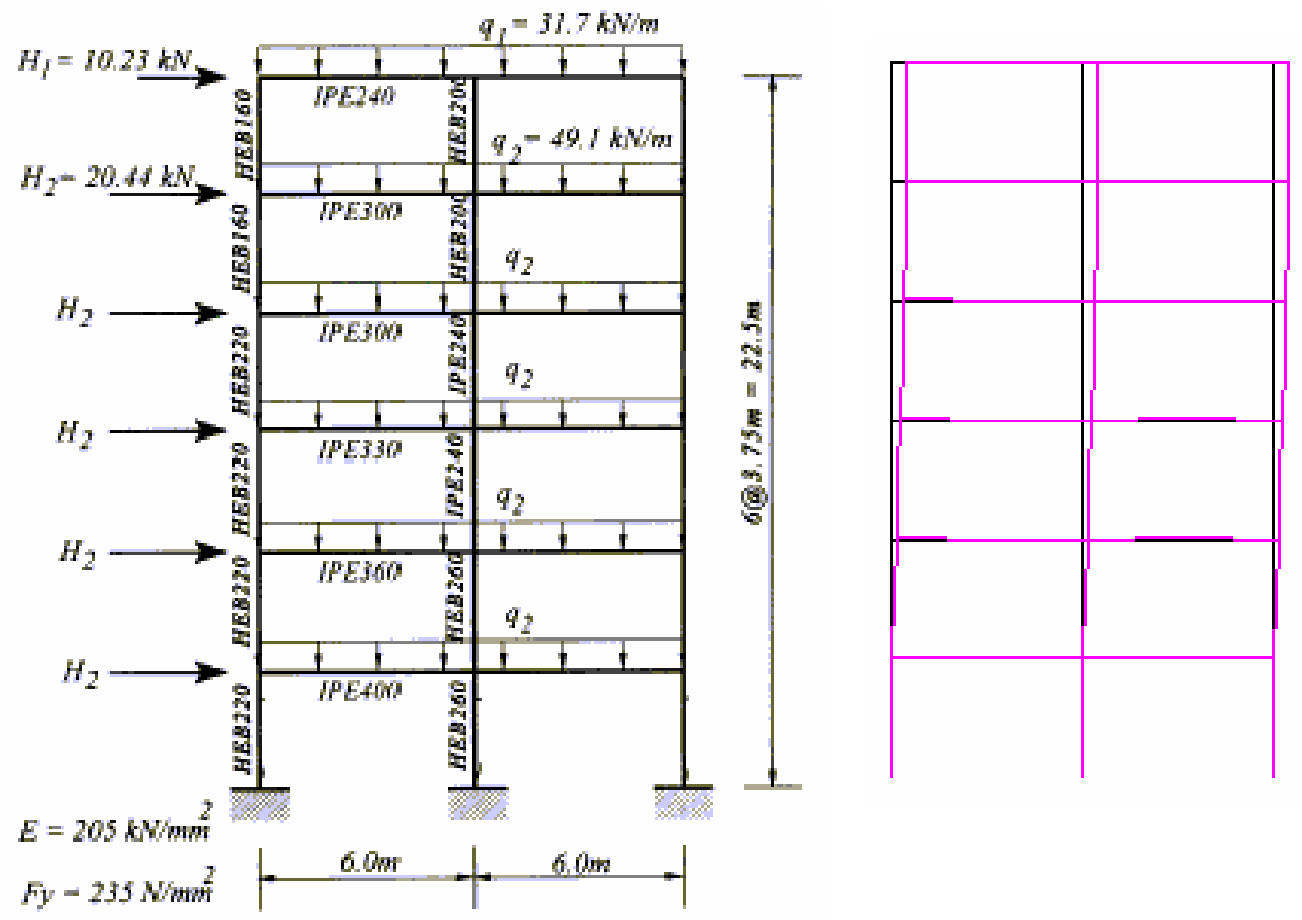

Figure 19. Loading, geometry definition and buckling mode.

\subsection{1-D Orbison Frame modified (Figure 20)}

The orbison frame has been modified duplicating the height in the 4 story, in this case the worst imperfection associated to the structure is a torsional global mode see Figure 20. This kind of imperfection can be easily taken into account with the methodology proposed.
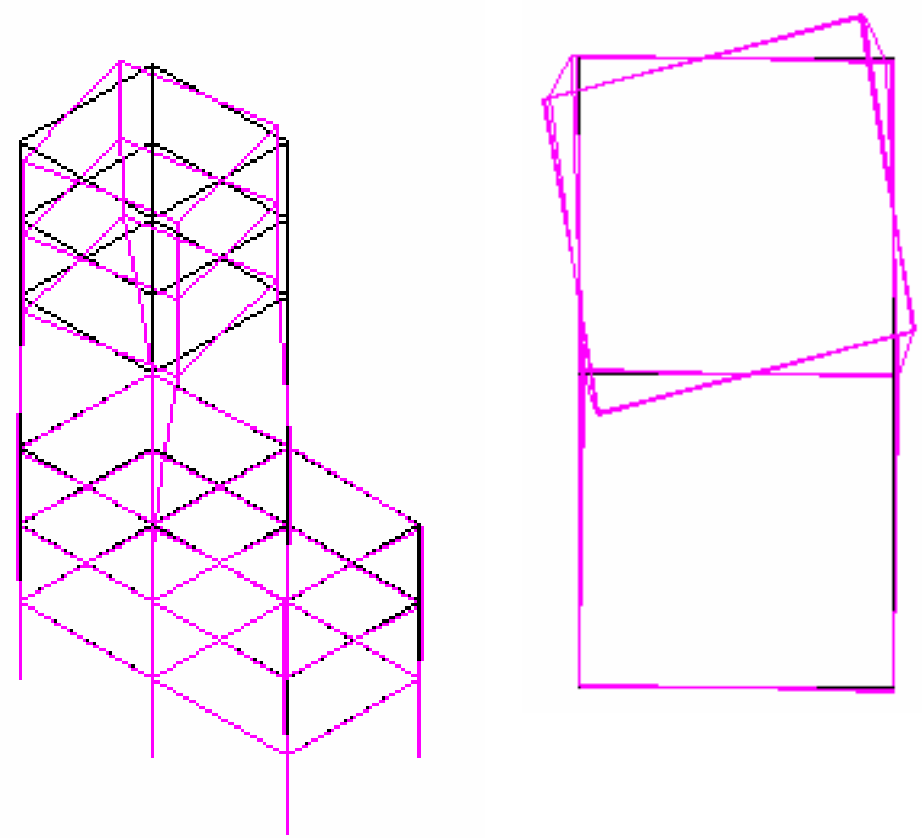

Figure 20. Geometric equivalent imperfection shape 


\subsubsection{Arches}

Parametric studies have been done for fixed and simply supported arch structures. The imperfection is compared with the given by the Spanish standard for steel bridges (RPM-95) [6]. As can be seen Figure 22 in RPM-95 the imperfection is independent of the slenderness. For the studies a cross section Hollow square section \# 400x400x10(mm) has been used. The geometry of the arches are parabolic given by $y=4 \cdot f \cdot x \cdot(L-x) / L^{2}$ :

\begin{tabular}{|c|c|c|c|c|c|c|}
\hline $\mathrm{f} / \mathrm{L}$ & \multicolumn{5}{|c|}{ Analysed cases } \\
\hline 0.1 & $1 / 10$ & $2 / 20$ & $3 / 30$ & $4 / 40$ & $5 / 50$ & $6 / 60$ \\
\hline 0.2 & $2 / 10$ & $4 / 20$ & $6 / 30$ & $8 / 40$ & $10 / 50$ & $12 / 60$ \\
\hline
\end{tabular}
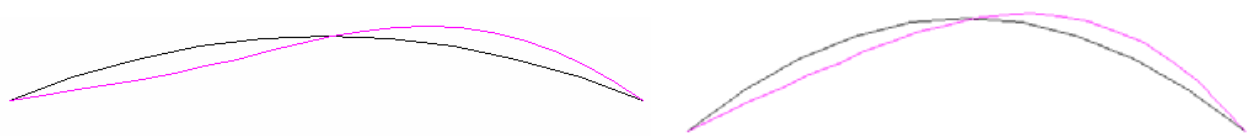

Figure 21. Geometric equivalent imperfection shape

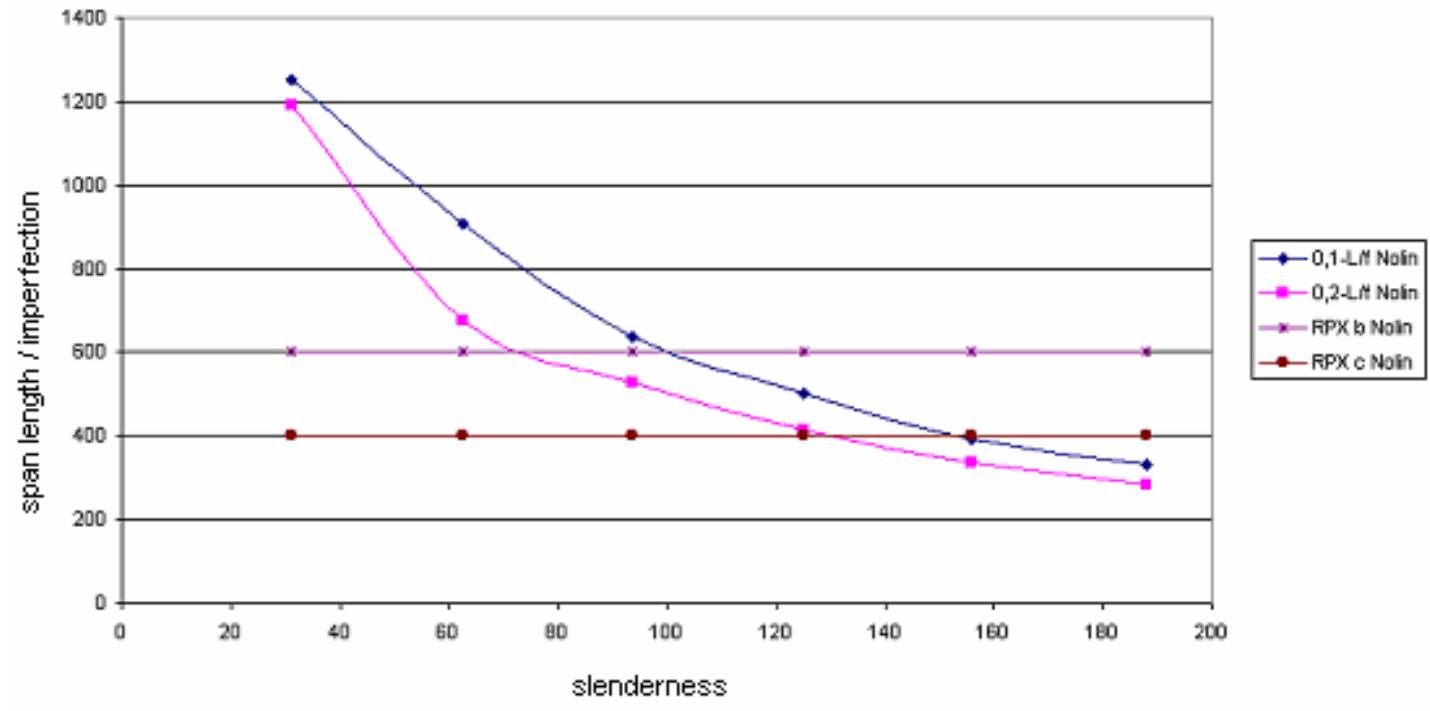

Figure 22. Comparison \{span length/imperfection\} vs slenderness, proposal vs RPM

The magnitude of the geometric equivalent imperfection must be dependent on the arch slenderness, and not independent as it is proposed by the RPM-95.

\section{Secondary effects associated with the first buckling mode (Figure 23)}

In a 2 span beam the buckling modes and the associated bending moment and shear force are obtained. These parameters are studied for different values of $\alpha=\mathrm{P}_{2} / \mathrm{P}_{1} \alpha=0,1,10,100$. The length of each span is $8 \mathrm{~m}$, and the inertia is $\mathrm{Iz}=551 \mathrm{~cm}^{4}$.

Figure 23. Loading, geometry definition 
In Figure 24 the buckling modes and stresses are ploted $\alpha=0$ (blue), $\alpha=1$ (black), $\alpha=10$ (green), $\alpha=100$ (red).

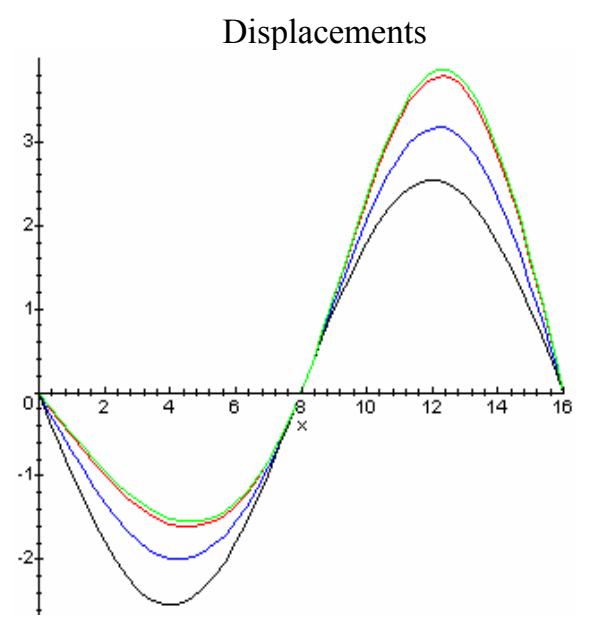

Bending moment $\mathrm{Mz}$

Shear force Qy

Figure 24. Geometric imperfection shape and associated bending moments and shear forces.

\section{Pitched roof frames}

Parametric studies have been done for fixed and simply supported structures, and it can be concluded that 2 buckling modes (Figure 25) are necessary, to obtain accurate results in this kind of structure.

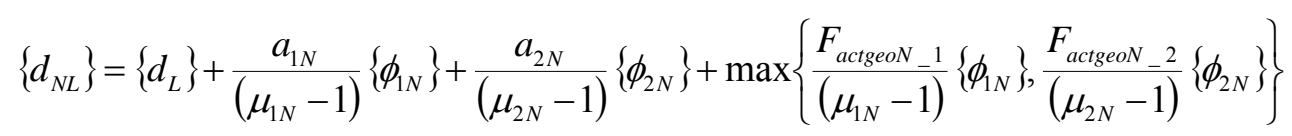

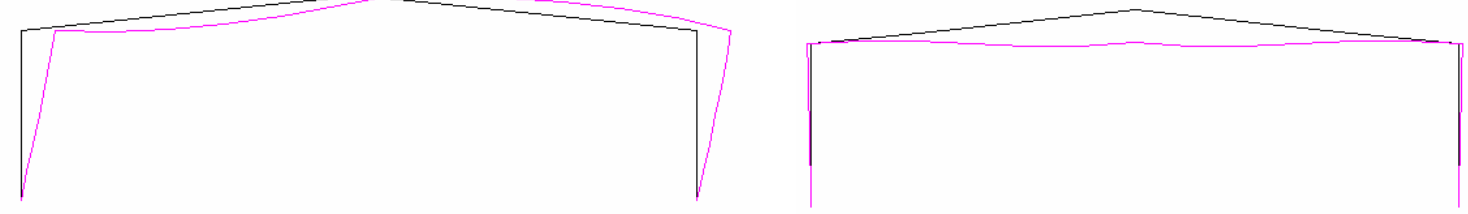

Figure 25. Usual buckling modes $\left\{\phi_{1} ; \phi_{2}\right\}$ of the pitched roof frames

\section{CONCLUSIONS AND FURTHER WORK}

In this paper, a practical second-order advanced analysis has been developed to estimate accurately the ultimate limit state of slender steel structures, performing the analysis of an structure with a geometric equivalent imperfection using only a linear and an initial stability analysis, further details are given in [7]. The main conclusions are:

- A simplified method to evaluate the second order effects induced by axial forces and bending moments using the orthogonality properties of the buckling modes has been proposed, in the current standards the second order effects due to strong bending moments are neglected. Also an analytical solution for the analysis of imperfect structures under primary constant axial forces and strong bending moment is presented.

- A generalization of Dutheil's theory, consistent with current standards, is presented to evaluate the geometric equivalent imperfection in any kind of structure accounting for all the key factors 
influencing steel frame behavior. In some codes the proposed member imperfection $\{\delta\}$ for the global analysis is taken independent of the slenderness to facilitate the definition of the imperfect structure, this idea goes in the right direction but, leads to inconsistent results when compared in the simply supported column with the numerical and experimental records, it is known that the imperfection depends on the slenderness as in Perry-Robertson or Dutheil formula.

- The buckling phenomenon is associated to movements exhibiting an understandable physical background and transparency, versus the use of interaction formulae with auxiliary coefficients ( $\omega$ in EA-95, $\chi$ in EC-3).

- In the present proposal the internal forces are:

o The linear internal forces (In the structure without imperfections)

o The amplification of the linear internal forces induced by the primary axial forces.

o The secondary effects induced by the axial load in the imperfect structure.

o The amplification of the linear internal forces induced by the primary strong bending moments.

o The secondary effects induced by the strong bending moments in the imperfect structure.

- The strength check is made at the section level with the "real" internal forces obtained from the analysis, avoiding complex interaction formulae at the member level.

- Buckling is analysed as a global problem, instead of a problem only related to the members with primary axial or bending internal forces, taking into account the interaction between the members of the structure.

- The method is applied to steel frames, pitched roof frames and arches. Comparing the results with the one's obtained with current standards (EA-95, EC-3, RPM-95):

o Frames: The Eurocode by means of member and frame imperfection tries to approach to buckling mode imperfection. Presenting the disadvantage that in a complex case is not clear which should be the direction of these imperfections.

o Pitched roof frames: It is necessary to work with two buckling modes to obtain accurately the second order effects.

o Arches: Simply supported, fixed and statically determinate (three hinge) arches have been studied, the conclusions are similar for all of them. The magnitude of the geometric equivalent imperfection is dependent on the arch slenderness, and not independent as it is proposed by the RPM-95.

\section{NOTATION}

$\begin{array}{ll}\mathrm{E} & =\text { Young modulus } \\ \mathrm{Iz} & =\text { Inertia about } \mathrm{z} \text { axis } \\ \mathrm{Iy} & =\text { Inertia about } \mathrm{y} \text { axis } \\ \mathrm{A} & \quad \text { Area } \\ \mathrm{G} & =\text { Shear modulus } \\ \mathrm{It} & =\text { Torsional modulus } \\ \mathrm{Ia} & =\text { Warping modulus } \\ \mathrm{p}_{\mathrm{x}} & =\text { Distributed load in direction } \mathrm{x} \text { (axial) }\end{array}$




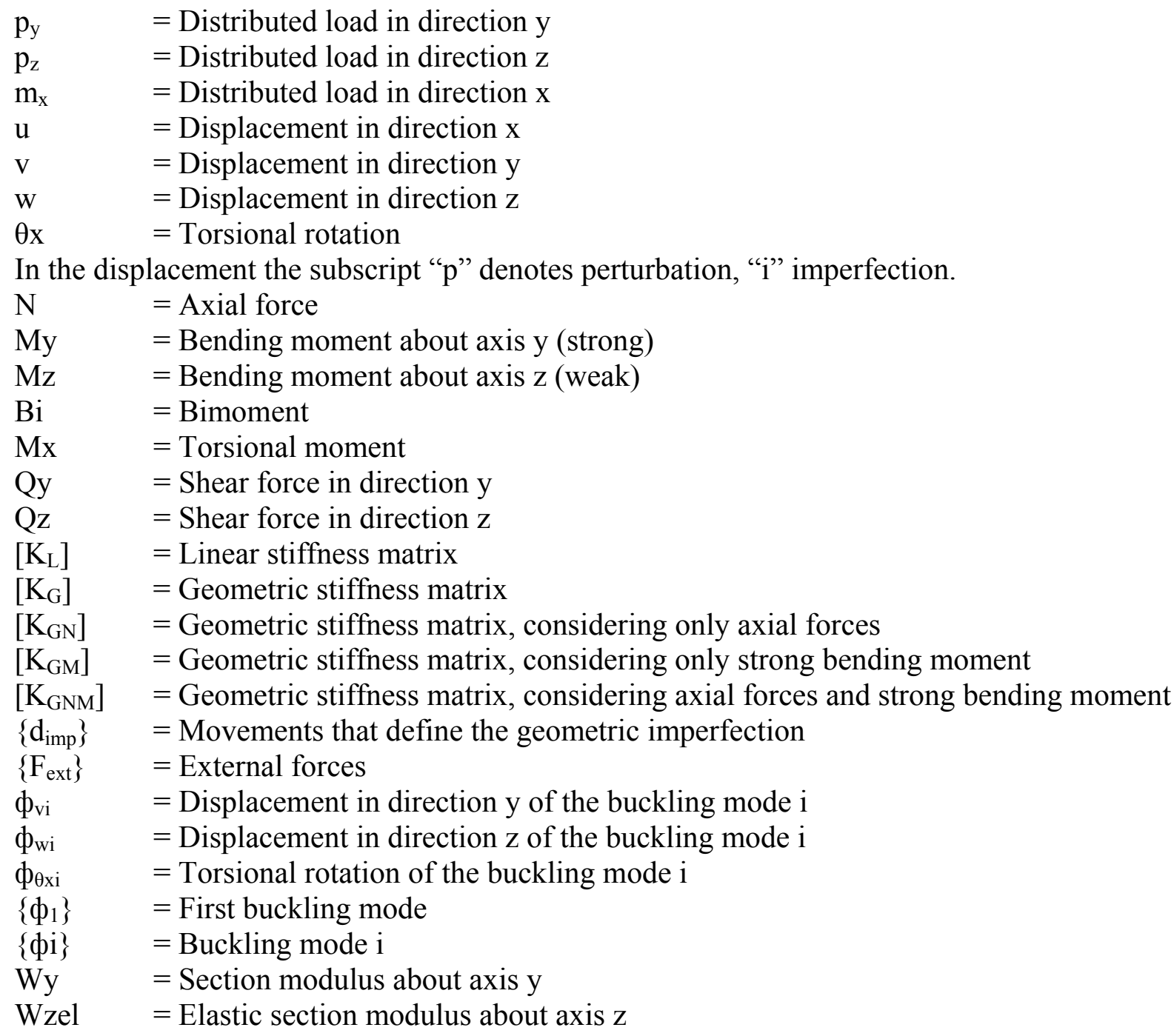

\section{REFERENCES}

[1] ENV 1993-1-1, "Eurocode 3: Design of steel structures, Part 1.1: general rules and rules for buildings", CEN, 1992.

[2] Chen, W.F. and Atsuta, T., "Theory of beam columns Vol. 2: Space behaviour and design". Mc Graw Hill, U.S.A., 1976.

[3] Chan, S.L. and Zhou, Z.H., "Second order analysis of frame using a single imperfect element per member", Journal of Structural Engineering, ASCE, 1995, 121(6), pp.939-945.

[4] Kim, S.E. and Chen, W.F., "Design guide for steel frames using advanced analysis program", Engineering Structures, 1999, 21, pp.352-364.

[5] Clarke, M.J., Bridge, R.Q., Hancock, G.J. and Trahair, N.S., “Advanced analysis of steel building frames", Journal of Constructional Steel Research, 1992, 23, pp.1-29.

[6] RPM-95, "Recomendaciones para el proyecto de puentes metálicos para carreteras". Ed. Ministerio de fomento, 1996.

[7] Aguero, A., "Metodo aproximado para estimar el estado limite ultimo en entramados metalicos esbeltos", Tesis Doctoral, Valencia, Spain. Ed. By Proquest, 2003.

[8] Crisfield, M.A., "Non-linear finite element analysis of solids and structures", volume 2, John Wiley and Sons, 1997. 
[9] Culver, C.G., "Initial imperfections in Biaxial Bending Equations", Journal of the structural Division, ASCE, 1966, 92(ST2), Proc. Paper 4772, April, pp.63-83.

[10] Timoshenko, S.P. and Gere, J.M., "Theory of elastic stability", McGraw Hill, New York, 1961.

[11] Trahair, N.S., "Flexural-torsional buckling of structures", E\&FN SPON, 1993

[12] Zienkiewicz, O.C. and Taylor, R., "The finite element method Solid Mechanics", Volume II, Butterworth-Heinemann, 2000. 